\section{Automatic determination of blood cholesterol}

\section{J. BOY From the Civil Hospital, Rheims, France}

Manual methods for measuring cholesterol are numerous, some simple, others complicated, and there is as yet no common agreement as to the value of all these techniques. The many causes of error have already been studied (Fürst and Lange, 1954; Rivin, Yoshino, Shickman, and Schjeide, 1958). Even in highly complicated methods, errors may arise at each stage of the analysis if the conditions are not identical, especially in unskilled hands. A method which gives excellent results when a small number of samples is being run will be faulty when applied to the determination of a series, because the conditions of time and temperature are not rigorously the same at the beginning and at the end of the series. It seems, therefore, that an automatic method might offer the means of a more exact determination of a large number of samples. Moreover, the automatic method permits the evaluation of the reproducibility of the reaction. So far it has been possible to transfer only simple manual methods to the automatic level.

\section{METHOD}

The reaction used is that of Pearson, Stern, and McGavack (1953) with the proportions of the reagents slightly modified (Boy, Bonnafé, and Mazet, 1960).

REAGENTS Two reagents are required, the first a mixture of acetic anhydrid, paratoluene sulphonic acid, and acetic acid. In $600 \mathrm{ml}$. of acetic anhydrid dissolve, without heating, $30 \mathrm{~g}$. of paratoluene sulphonic acid (this is dangerous only when heated in a direct flame). To dissolve the mixture in the acetic anhydrid is easy but it may be slightly cloudy with certain qualities of paratoluene sulphonic acid; this is of no importance. Complete to 1 litre with glacialaceticacid $(400 \mathrm{ml}$.). The mixture does not develop too much heat with glacial acetic acid of good quality.

The second reagent is pure sulphuric acid (R.G.).

APPARATUS The apparatus consists of one sampler, one proportionating pump, several jacket coils $16 \mathrm{~cm}$. long, one photometer, and one recorder ${ }^{1}$.

The kind of tubes used for pumping is important. The sulphuric acid should be pumped with a fluoran tube ${ }^{1}$ which alone will resist its corrosive action, although it will not withstand the mixture of acetic anhydrid, paratoluene sulphonic acid, and acetic acid. For this reagent siliconized tubing must be used which is re-

Received for publication 18 June 1962

'All obtainable from Technicon International Ltd. (Autotechnicon), Hanworth Lane, Chertsey, Surrey.

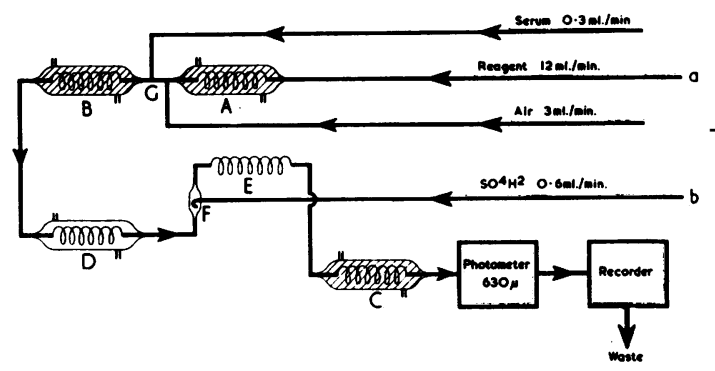

Fig. 1. A, B, C Jacket coil at $65^{\circ} \mathrm{C}$. D Jacket coil at $15^{\circ} \mathrm{C}$. E Ordinary double mixing coil. F Special mix - -5 ing fitting. G Special ultracapillary $T$. a Siliconized용 tubing. b Fluoran tubing.

sistant if the reacting agents are not allowed to stand in the tube, which should be rinsed after using, and then immersed in water for several hours. The samples are placed on the sampler in alternate cups, leaving every other cup empty. Figure 1 illustrates the arrangement of $\vec{z}$ the tubes.

PROCEDURE A stream of reagent 1 is pumped at the rate $\frac{\rho}{\supset}$ of $12 \mathrm{ml}$. a minute, then, after having been heated to $\vec{\varphi}$ $65^{\circ} \mathrm{C}$. in jacket coil $\mathrm{A}$, is mixed with a stream of serum $\mathrm{S}$ flowing at $0.3 \mathrm{ml}$. a minute. The mixture is heated and mixed in a second jacket coil (B) at $65^{\circ} \mathrm{C}$. It is then cooled by passing through a third jacket (D) outside which ordinary tap water is running at $15^{\circ} \mathrm{C}$. The sulphuric acid is mixed at the rate of $0.6 \mathrm{ml}$. a minute and takes place in an ordinary coil, the fluid then passing $\mathscr{\perp}$ through a final jacket coil (C) in which water is circulating $\Rightarrow$ at $65^{\circ} \mathrm{C}$. The colour develops and is read with a photometer and recorded.

The standards for the reaction are made with Versatol ${ }^{2}$ Since the reaction strictly follows the Beer-Lambert law, higher values are easily calculated by multiplying the optical density by $2,3,4$, so that the absorptions correspond to 2,3, and 4 times the value of the Versatol.

The extraction of the cholesterol by means of a solvent of the user's choice, followed by the recovery of the extract by a volume of glacial acetic acid equal to the quantity of the sample, permits the analysis of strongly icteric sera and of haemolytic sera.

\section{DISCUSSION}

The automatic determination of ch

The automatic determination of cholesterol (which weN have been practising for three years) has shown the N importance of factors insufficiently regarded in the ${ }^{\omega}$ manual methods.

Pearson's method presents the advantage of being carried out on pure serum without extraction, which $\Phi$ eliminates from the start the numerous errors caused by? extraction in work on a series. A slight modification of 0 the original technique permits of a clear mixture of serum and acetic anhydrid, which is an essential con- $\stackrel{\mathbb{D}}{\Omega}$ dition for an automatic method. Moreover, the presence $\frac{\mathcal{D}}{\mathcal{O}}$ of the paratoluene sulphonic acid stabilizes the colour of $\frac{}{\sigma}$

${ }^{2}$ Versatol: Warner-Chilcott

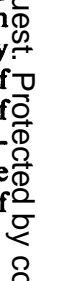




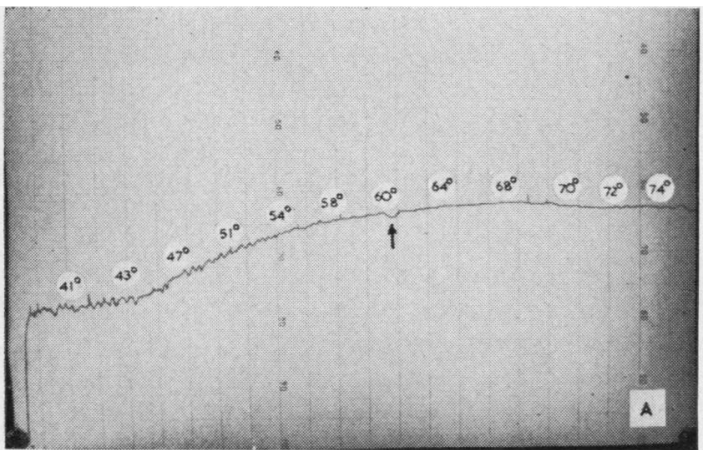

FIG. 2. Influence of continuous variation in temperature on the colour of Liebermann reaction. Serum and reagents are continuously pumped.

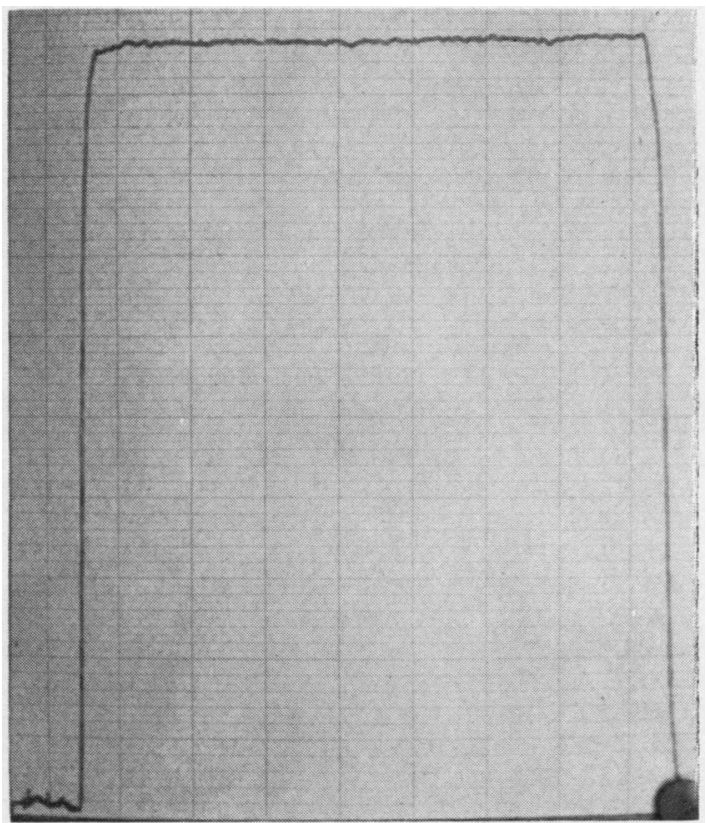

FIG. 3. Serum and reagents are pumped continuously at $65^{\circ} \mathrm{C}$. The colour of the Liebermann reaction is constant (+ $0.5 \%$ absorption).

the Liebermann's reaction, which is important. Furthermore, Liebermann's reaction has good specificity. Only certain sterols included in the insaponifiable can give it. Salkowski's coloration, used in Zak's technique, can be developed by other compounds than sterols and accidental impurities in reagents can produce it.

The three advantages of Pearson's reaction are limpidity of the mixture, specificity, and greater stability. Pearson's method, however, has been criticized for giving too high results, which are attributed to the colour of the serum or to a 'protein effect'. This does not seem to be true if the precaution is taken of cooling the mixture of 
which, when the automatic apparatus is used, is valid.

A more serious difficulty is that of standardization and is not peculiar to Pearson's method; it is solved by the use of a commercial standard serum of the Versatol type. Only comparison with a standard serum of good quality is valid (Rivin et al., 1958), for artificial titrated solutions never have exactly the same degree of humidity as the serum and the slightest difference in the quantity of water causes enormous differences in the intensity of Liebermann's or Salkowski's reactions.

Since the time of the circuit is rigorously constant, it has been possible to study the influence of continual variations in temperature (Fig. 2). A temperature of $65^{\circ} \mathrm{C}$. appears best because between $56^{\circ} \mathrm{C}$. and $72^{\circ} \mathrm{C}$. variations have very little effect on the development of the colour; thus even a small variation in the thermostat does not produce appreciable errors (Fig. 3). Furthermore, at this temperature the levels of the colour for free cholesterol and for esterified cholesterol are identical (Girard and Assous, 1962).

\section{SUMMARY}

The use of an automatic apparatus with a strictly constant time for the reaction and the mixing processes eliminates the errors observed in the manual methods.

An installation is proposed in which the temperature is fixed in such a way that reproducibility is good such as was never achieved manually with series including many samples.

\section{REFERENCES}

Boy, J., Bonnafé, M., and Mazet, J. B. (1960). Ann. Biol. clin., 10-12, 335.

Fürst, B. Jr., and Lange, R. (1954). Scand. J. clin. Lab. Invest., 6, 60. Girard, M., and Assous, E. (1962). Ann. Biol. clin., 3, 335.

Pearson, S., Stern, S., and McGavack, T. H. (1953). Analyt. Chem., 25, 813.

Rivin, A. U., Yoshino, J., Shickman, M., and Schjeide, O. A. (1958). J. Amer. med. Ass., 166, 2108.
Separation of human lymphocytes and monocytes using an 'oil bottle'

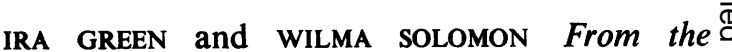
Haematology Department, Laboratory Division, ڤे Montefiore Hospital, New York, N.Y.

Several methods of separating lymphocytes and monocytes based on specific gravity differences between $\overrightarrow{7}$ lymphocytes and other types of cells have been described (Kline, 1955; Ottesen, 1954; Seal, 1959; Tullis, 1952; $\vec{\sigma}$ Ventzke, Perry, and Crepaldi, 1959). The viability of the ? isolated cells has usually been tested by indirect methods $\overrightarrow{\vec{V}}$ (Jago, 1956; Lalezari, 1962; Lapin, Horonick, and $\infty$ Lapin, 1958). The technique to be described is simple, 을 requiring only one centrifugation; it is reliable, and uses equipment which can be readily purchased. No haemo- 3 lytic agents are used to eliminate the red blood cells. The $\stackrel{0}{\bar{O}}$ viability of the cells obtained using this technique has $\stackrel{3}{J}$ been directly assayed by the ability of these cells to $\vec{\varphi}$ proliferate in subcutaneously placed micro-diffusion of chambers in human subjects.

METHOD

All glass surfaces were siliconized and all equipment and reagents were sterilized. Sixty to $80 \mathrm{ml}$. of blood was collected with a plastic tube ${ }^{2}$ and led directly into a $100 \mathrm{ml}$. graduated flask containing $20 \mathrm{ml}$. of $6 \%$ dextran in isotonic saline (M.W. 188,000$)^{3}$ and $1 \mathrm{ml}$. of $10 \%$ E.D.T.A. The flask was stoppered and inverted gently eight times. The erythrocytes were allowed to settle by gravity for $\mathbf{2 0}$ minutes at room temperature. The supernatant plasma was placed in a $100 \mathrm{ml}$. 'oil bottle' with a $0.5 \mathrm{ml}$. stem $4 \mathrm{~cm}$. long, with a diameter of $3.8 \mathrm{~mm}$. (Corning Glass Co., Corning, N.Y.). The 'oil bottle' was then spun at 2,500 r.p.m. for 30 minutes in a no. 2 international centrifuge. To hold the 'oil bottle' special cups (international no. 395) were used.

All the cellular elements of the plasma were now layered in the narrow dependent stem of the 'oil bottle' with the platelets uppermost, followed by the lymphocytemonocyte layer, then the polymorphonuclear cell layer, $\sigma$ and finally a button of red cells at the bottom. The line $N$ of demarcation between these layers was easily seen $O$ (Fig. 1). The supernatant plasma was poured off. The $\omega$ thick platelet layer was removed using a Pasteur disposable pipette ${ }^{4}$ and a rubber bulb.

To remove the lymphocyte-monocyte layer a narrow glass pipette $10 \mathrm{~cm}$. long was fashioned from the long $\stackrel{\mathcal{Q}}{\rightarrow}$ stem of a disposable pipette. The tip of this pipette should

'Supported by United States Public Health grant no. C-4788.

'Blood Collection Set no. 36, Abbott Labs., Chicago, Ill.

'Pharmachem Corp., Bethlehem, Pa.

'Transpets, Clay-Adams, New York City

Received for publication 25 June 1962 